\title{
Perspectives on the clinical significance of functional pain syndromes in children
}

This article was published in the following Dove Press journal:

Journal of Pain Research

7 October 2015

Number of times this article has been viewed

\author{
Molly C Basch ${ }^{1,2}$ \\ Erika T Chow ${ }^{1,3}$ \\ Deirdre E Logan ${ }^{1,4}$ \\ Neil L Schechter ${ }^{4}$ \\ Laura E Simons 1,2,4 $^{2}$ \\ 'Division of Pain Medicine, \\ Department of Anesthesiology, \\ Perioperative and Pain Medicine, \\ Boston Children's Hospital, ${ }^{2}$ Boston \\ Children's Hospital, Center for \\ Pain and the Brain, PAIN Research \\ Group, ${ }^{3}$ Boston University School \\ of Medicine, Boston University, \\ ${ }^{4}$ Department of Psychiatry, Harvard \\ Medical School, Boston, MA, USA
}

\begin{abstract}
Functional pain syndromes (FPS) characterize a subset of individuals who experience pain and related symptoms and disability without clear structural or disease etiology. In the pediatric population, FPS hold high clinical importance due to significant prevalence rates and potential to persist into adulthood. Although extensive research has been executed to disambiguate FPS, the syndromes that fall within its spectrum remain conceptually complex and sometimes ill-defined. This paper provides an overview of available research on the classification and multifaceted etiology of FPS in youth and their effects on interpersonal, psychological, and familial function. Vital aspects of a successful multidisciplinary approach to treating this population are described; however, it is evident that future research requires more longitudinal studies.
\end{abstract}

Keywords: overlapping chronic pain, functional pain, primary pain disorders, pediatrics, biopsychosocial model

\section{Introduction}

Functional pain syndromes (FPS) are a diagnostic group of conditions that remain loosely defined. Pain is often a warning signal from the body indicating an abnormality in structure or function. However, there is a subset of patients who experience pain and are subject to symptoms, suffering, and disability with unclear disease etiology or biomechanical cause. Many patients who experience FPS also experience clusters of symptoms that can affect a wide array of systems, often due to a combination of varying physiological, affective, and cognitive influences. ${ }^{1}$ As a result, physicians have the difficult task of labeling a cluster of symptoms that do not neatly fit into a diseasedriven diagnostic category and implementing a treatment plan that at times relies on speculation. This is due to several reasons: 1) these diseases often present with a wide variety of symptoms and so the diagnostic criteria are vague and constantly under revision; ${ }^{2-6} 2$ ) these diseases arise from a complex mix of biological, psychological, and interpersonal factors; ${ }^{7-10}$ and 3 ) these diseases often share similarities with each other and it can be difficult to make a definitive distinction, ${ }^{11}$ and frequently co-occur, making definitive distinction difficult. As a result, these diseases can often be misdiagnosed, especially in a pediatric population. ${ }^{12}$

An investigation conducted by the Pain of Unknown Origin in Children Study Group one decade ago supports this premise. The study assembled a panel of 17 Dutch pediatricians who work in psychosomatic medicine and presented them with the medical reports and standardized psychiatric assessment of 134 children who had FPS for more than 3 months. ${ }^{13}$ All the participating pediatricians were asked to use
Division of Pain Medicine, Department of Anesthesiology, Perioperative and Pain Medicine, Boston Children's Hospital, 2 I Autumn Street, Boston, MA 02215, USA Tel + I 6179194677

Fax + I 6177300759

Email laura.simons@childrens.harvard.edu 
the information to diagnose the children, with a consensus being defined as agreement among more than $80 \%$ of the pediatricians. Consensus for the underlying cause was only found for $47 \%$ of the cases, and consensus regarding the appropriate diagnostic approach was reached for $63 \%$ of the cases. ${ }^{13}$ Further work needs to be done on developing a diagnostic procedure that is reliable and encompasses most if not all FPS. ${ }^{14}$

\section{Lack of a common language hampers clinical and scientific progress}

Too often, a patient receives a diagnostic label or labels that reflect the specialist's area of expertise as opposed to the patient's overall experience. For example, a patient with excessive bowel symptoms might present to a gastroenterologist who diagnoses her with irritable bowel syndrome (IBS), whereas a patient who has widespread muscle pain and tenderness may go to a rheumatologist who diagnoses him with fibromyalgia. ${ }^{15}$ A recent study showed that these different conditions may actually reflect a common entity but have labels that reflect the specialists' area of expertise. ${ }^{15}$ The most common diagnoses that reflect this functional overlap in pediatrics include headache, functional gastrointestinal disorders (FGIDs), fibromyalgia, and chronic fatigue syndrome/myalgic encephalomyelitis (CFS/ME). ${ }^{15,16}$ The involvement of organ-system specialists in evaluating and diagnosing these complex chronic pain conditions mean that very little research has been done across disciplines to determine if these conditions are truly different or do in fact reflect a common entity.

Research into the field of FPS is further hampered by the fact that the same symptom cluster is associated with various diagnostic names, for example: somatoform disorder, ${ }^{16}$ somatization, ${ }^{17}$ functional somatic syndrome, ${ }^{18}$ bodily distress disorder, ${ }^{19}$ central sensitization syndrome, amplified pain syndrome, and primary pain disorder. ${ }^{20}$ As a result, a literature search into the area of FPS is very disjointed and requires use of a wide variety of keywords. To further complicate matters, the term "somatoform disorder" was introduced by the Diagnostic and Statistical Manual of Mental Disorders-III (DSM-III). ${ }^{21}$ However, the DSM-III handling of somatoform disorders focused primarily on somatic symptoms caused by psychological rather than biomedical factors. The publication of the DSM-IV expanded the definition of somatic symptoms to include those "not fully explained by a general medical condition", thereby removing the etiologic divide between psychological and biomedical factors. The classification still had many flaws. ${ }^{22}$ $D S M-V$ has changed the term to somatic symptom disorder, a name that had not been previously misused. In this iteration of the diagnosis, the manual's authors completely removed any distinctions between medically explained and medically unexplained somatic symptoms. ${ }^{19}$ However, the classification includes somatization in the context of other diseases (eg, cancer and diabetes), so it may not be the most optimal term for uniquely capturing FPS. ${ }^{19}$ To further complicate matters, the fact that somatic symptom disorders are included in the $D S M$ at all is controversial - some doctors think that these disorders have a biological cause that has not been identified yet, while others think that the disorders have a purely psychological cause. ${ }^{19}$

\section{What's in a name?}

The label used for these diseases matters because it affects perception by patients, doctors, and the public alike. A cohort of CFS patients were asked to choose their three most preferred terms from a list of commonly used names for FPS. ${ }^{23}$ The most endorsed term was "persistent physical symptoms", followed by "complex physical symptoms" and "medically unexplained physical symptoms", reflecting a desire to stress the physical nature of these diseases. ${ }^{23}$ Another study surveyed 844 members of the general public on their most preferred clinical term for FPS, and the most commonly selected names were "persistent physical symptoms" (20\%), "functional symptoms" (17\%), and "medically unexplained symptoms" (15\%). ${ }^{24}$ Even the name of each individual FPS disease matters. Medical trainees presented with CFS patients and prompted with either CFS, ME, or Florence Nightingale disease attributed different causes and prognoses to the patients depending on which name they were provided in the study. ${ }^{25}$ Another similar study on the labeling of CFS showed similar results. ${ }^{26}$ Terminology and diagnostic criteria for the condition also affect how people are diagnosed. For example, 2,674 adolescents were evaluated with DSM-III somatization disorder criteria. The prevalence was too low in the 4- to 11-year-old group for a reliable conclusion, but in the 12 - to 16 -year-old age group, $11 \%$ of girls and $4.5 \%$ of boys fit the criteria. ${ }^{27} \mathrm{~A}$ later study then used the $D S M-I V$ somatization disorder criteria with a group of 14- to 24-year olds, and found that the prevalence was only $2.7 \%$, but significantly more of the same respondents met criteria for clinically significant FPS, resulting in a prevalence rate of $12.6 \%{ }^{27}$ It is clear that the terminology of these diseases, both for the individual diseases and the overarching term for FPS, still need to be clarified and reworked. ${ }^{21}$ 


\section{FPS by the numbers}

The issue of pediatric FPS is not one to be taken lightly because it affects a significant patient population. Exactly how many patients struggle with this issue is unknown because little work has been done on the epidemiology of all FPS. King et a ${ }^{28}$ reported in a meta-analysis that $11 \%-38 \%$ of children have chronic pain. It has been estimated that a range of $0.03 \%-1.29 \%$ of children suffer from ME/CFS. ${ }^{6}$ Pediatric weekly headaches are reported in $10 \%-30 \%$ of children and are the reason for $1 \%-2 \%$ of pediatric outpatient visits. ${ }^{16}$ A cross-sectional study of Norwegian adolescents showed that the 1-year prevalence rate for tension headache was $58 \%$, and the point prevalence for any kind of headache was $38 \% .^{29}$ Functional or recurrent abdominal pain is reported in $7 \%-25 \%$ of school-aged children and is the reason for $2 \%-4 \%$ of pediatric visits. ${ }^{16}$ Pediatric fibromyalgia has been reported anywhere from $1.2 \%-6.2 \%$ of children. ${ }^{2}$ Eminson $^{27}$ reported that studies done on FPS in various countries showed $6 \%-20 \%$ of pediatric patients complaining of somatic symptoms. These prevalence rates are associated with significant health-care expenditure. It has been estimated that the average annual costs associated with FPS in the US total over $\$ 11,000$ among some adolescent patients. ${ }^{30}$

\section{Theories to explain FPS}

FPS can be caused by a myriad of physiological/biological and psychological influences. ${ }^{1}$ The biology behind FPS is still poorly understood, and no work has been done on differences between children and adults. As a result, the theories that will be underlined below apply to the development of FPS in the general population. Some work has been done on understanding the mechanisms underlying specific FPS. For example, a recent study found that fructose intolerance/malabsorption can contribute to the pain symptoms of FGIDs, ${ }^{31}$ and another study found that more than half of a sample of 41 pediatric patients with chronic widespread pain showed signs of smallfiber polyneuropathy. ${ }^{32}$ However, a few unifying theories on the mechanisms behind all FPS have been proposed and are outlined below. It is generally considered that patient symptoms can be understood through the lens of one or more of these theories, with some relying more heavily on the biological/physiological substrates of the condition, whereas others highlight the cognitive-affective contributors.

\section{Neuronal sensitization theory}

Patients who have repeated sensations of pain can develop memory traces on a neuronal level that increase sensitivity to further sensations. ${ }^{33}$ In these cases, a typically benign sensation can be interpreted as pain due to the neuronal memory traces. Over time, the memory trace can rewire larger portions of the brain and increase its range until a symptom memory matrix has been sensitized, and several physical symptoms can be triggered at once with increasing intensity. ${ }^{34}$ Hypersensitivity has been shown in children with FGIDs, Crohn's disease, fibromyalgia, and chronic fatigue. ${ }^{35-37}$

\section{Immune system sensitization theory}

The body can trigger an immune response to danger signals and pathogen-associated molecular patterns. The resulting release of cytokines that normally tells the brain to change the focus of its priorities can lead to increased sickness behavior, metabolic alterations, and malaise. ${ }^{38}$ This cytokine-induced sickness behavior can persist when the innate immune system is chronically activated, and prolonged activation of this system can restructure a patient's physiology and induce mood disorders..$^{39}$ These cytokines can also amplify the perception of pain due to the effect that proinflammatory mediators have on the central nervous system, thereby increasing pain, sleep disturbance, and fatigue. ${ }^{40}$

\section{Endocrine dysregulation theory}

Dysregulation of the hypothalamus-pituitary axis' (HPA) ability to regulate the body's response to stress has been found in patients with FPS. Studies have shown that many patients with FPS have cortisol irregularities..$^{41} \mathrm{~A}$ theory for the dysfunction of the HPA is that prolonged activation creates a "burnout" effect and downregulates the HPA chronically, leading to hypocortisolism. ${ }^{33}$ Another theory is that the hypocortisolism is a protective mechanism. ${ }^{33} \mathrm{~A}$ final theory proposes that the HPA fluctuates in activity, with hypoalgesia during acute stress and hyperalgesia during chronic stress. ${ }^{41}$ Therefore, it is clear that the axis does play some role in FPS, but it is not yet fully understood.

\section{Signal filter theory}

The body constantly sends the brain sensory information, but the signals are filtered to protect the brain from being overstimulated by information. In patients with FPS, it has been proposed that a malfunctioning filter causes the patients' brains to become overloaded with endogenous and exogenous information and increases the number of physical sensations that the patient experiences. ${ }^{33}$ Rief and Broadbent ${ }^{34}$ proposed that factors that can decrease filter activity include selective attention, infections, health anxiety, depressive mood, and lack of distraction. 


\section{Somatosensory amplification theory}

The concept underlying this theory is attention. A patient who experiences a physical sensation and focuses his/her attention on this sensation develops certain behaviors and cognitions that amplify his/her perception of the sensation. ${ }^{33}$ The amplification feeds itself back into a cycle of enhanced attention and pain. There are limitations to this theory, however. The original theory focused on the experience of hypochondriasis, not patients suffering from FPS. ${ }^{34}$ Additionally, while there has been some work with children indicating that somatosensory amplification increases the risk of some pains but not others (eg, back pain but not headache in adolescent girls ${ }^{42}$ ), most researchers agree that amplification can only explain a portion of the development of FPS. ${ }^{43}$ Along similar lines is the abnormal proprioception theory, illustrated in a study by Scholz et $\mathrm{al}^{44}$ that showed that patients with FPS had more precise but not necessarily more intense proprioception. The implications of this are still not well established, but Rief and Broadbent ${ }^{34}$ interpreted it to suggest that patients with FPS perceive physical sensations more precisely, so that normally minor physical symptoms could be perceived as more amplified and threatening.

\section{Autonomic nervous system dysfunction}

Following a period of distress or attention, a healthy body enters a rest state that is accompanied by a decrease in heart rate associated with the parasympathetic nervous system (PNS) ${ }^{33}$ However, in patients with FPS, there is evidence that the PNS is dysregulated and is unable to reduce the heart rate during the rest state, thus leading to chronic elevated heart rate and stress. ${ }^{33}$ This association has been shown in children with FGIDs, ${ }^{45}$ but not in a general pediatric patient population with FPS. Interestingly, this association may change with age, because a study found that FPS is associated with decreased PNS activity in patients aged $\leq 52$ years, whereas patients with FPS aged $>52$ years had increased PNS activity. ${ }^{46}$

\section{Illness behavior theory}

The concept behind this theory is that a patient's beliefs influence his/her behavior, which can then influence the physiologic response. The fear avoidance model is a conceptualization of this theory where fear and avoidance of activities due to pain result in worsening biopsychosocial functioning. It has been validated for pediatric chronic pain, ${ }^{47}$ but not specifically for FPS.

\section{Sensitivity theory}

Departing from the sensitization theory, this theory proposes that some patients are vulnerable to developing FPS based on underlying genetics. There has not been much evidence for genetic predisposition, but there is evidence that genetic variants can lead to variability in inflammation, which would alter the degree to which immune system sensitization could contribute to the development of FPS. ${ }^{40}$ Genetic variability can also change the stress response in an individual, altering how endocrine dysregulation and PNS dysfunction can affect FPS. Additionally, there is evidence that when a pregnant female is exposed to a significant stressor, the resulting stress response in her body can cross the placenta and alter the fetus's brain, endocrine, nervous, and immune function. ${ }^{48}$ However, these mechanisms are still largely unexplored. Some other possible predisposition theories attribute FPS to preexisting personality traits, such as self-protective organization and insecure attachment, as well as environmental factors, such as abuse, parental transmission, and stress. ${ }^{33}$ These factors will be explored later.

\section{Biopsychosocial model}

Incorporating elements of several theories described above, the biopsychosocial model proposes that FPS is a selfperpetuating cycle that involves interacting factors from physiological, cognitive, and affective domains. It also takes into account the patients' cognitions as well as any external factors that would predispose or facilitate FPS. ${ }^{33}$ As a result, the biopsychosocial model provides a cohesive approach to FPS. Cognitive behavioral therapy (CBT), a psychological treatment approach based on this model, is validated and utilized in treating children with FPS and is generally combined with exercise and certain pharmacological approaches. ${ }^{49}$

Despite the progress made in identifying the above mechanistic theories, the FPS pediatric population remains widely heterogeneous, making classification for research and treatment purposes extremely difficult. Similar barriers have been recognized within the pediatric headache population..$^{50}$ Connelly and Bickel ${ }^{50}$ suggested employing the use of a bottom-up approach with large sample, population-based data in order to further identify typical mechanistic pain patterns and characteristics. Utilizing this approach for FPS could provide benefit by narrowing the focus on possible underlying mechanisms and facilitate categorization for future research studies.

\section{The familial context in FPS}

Beyond genetic and biological vulnerabilities that are present at birth, there are several internal and external psychosocial factors that have been hypothesized to exacerbate or potentially increase the likelihood of the development of FPS. 
For example, insecure attachment in children has been shown to lead to somatization, especially in adult patients. ${ }^{51-53}$ No work has been done yet on pediatric patients with FPS and their attachment styles, but Kozlowska ${ }^{54}$ recently proposed an intervention for children with FPS that addresses attachment. ${ }^{55}$ Self-protection is related to attachment. Children can react to threats from close relationships by either an inhibitory, excitatory, or balanced emotional response. ${ }^{56}$ Children tailor their reactions according to how a parent reacts to their distress. If parents fail to respond, children develop an inhibitory display of their distress. If parents are "predictably unpredictable", the child will tend to display their distress in exaggerated ways. Parents who respond predictably and in comforting ways lead to a child who displays attachment and distress signals that are appropriate to the situation. Kozlowska and Williams ${ }^{56}$ found that children who demonstrate inhibitory or excitatory self-protective mechanisms are at greater risk for FPS. Anxiety has also been shown to have a significant association with development of FPS; in particular, children with panic disorder and separation anxiety disorder are at higher risk of somatization. ${ }^{57}$ Additionally, increased stress induced by a struggle to control people around us (agonistic striving) is significantly associated with increased somatization, and the association is especially apparent in people who have low pain tolerance. ${ }^{58}$ This association is seen in both a pediatric and adult population.

FPS can also be induced by exogenous factors. Children who have parents with chronic pain have been shown to have significantly increased insecure attachment, internalizing and externalizing, and poor biopsychosocial functioning. ${ }^{59,60}$ Although this association has not been directly linked to the development of FPS, these are all precipitating factors that increase a child's sensitivity to developing FPS. Parents with chronic pain who catastrophize about their own pain also tend to have overprotective responses to their child's pain and increase somatization in their children with IBS. ${ }^{61}$ While there has been some discussion about early childhood abuse causing FPS, there has been no evidence to support this claim. ${ }^{62,63}$ There is evidence that maladaptive parenting behaviors can contribute to somatization. For example, paternal rejection and/or hostility are correlated with increased somatization in IBS patients. ${ }^{64}$ Lastly, family life as a whole can influence the development of FPS. Family disorganization, poor family cohesion, and families less interested in political, social, intellectual, and cultural activities predict development of somatic complaints in adolescent girls in particular. ${ }^{65}$

One last potential cause of pediatric FPS that must unfortunately be accounted for is Munchausen's syndrome by proxy, otherwise known as fabricated or induced illness, as well as Munchausen's syndrome. Caretakers have been known to induce or fabricate illness, such as abdominal pain in their children. ${ }^{66}$ Potential motivations for this behavior include extreme illness anxiety, confirmation that the child is indeed ill, material gain, maintenance of a close relationship with the child, a need for attention, and deflection away from a child's behavioral problems. ${ }^{66}$ Not only does this parenting behavior subject children to unnecessary hospital visits and potential additional serious harm, it has also been shown to decrease biopsychosocial functioning in these children. ${ }^{66}$ However, Munchausen's syndrome is also seen in some children. Patients can induce symptoms by injuring themselves, disconnecting medical equipment, switching patient charts, and interfering with test samples. ${ }^{67}$ While this behavior is most common in women aged 20-40 years old, it has been reported in children as young as 8 years of age. ${ }^{67}$ Jaghab et $\mathrm{al}^{67}$ outline several cases of pediatric Munchausen's syndrome and the implications of the behavior. Both caregiver and patient illness fabrication should be potentially considered when diagnosing symptoms that seem inexplicable. Some even posit that it is possible for Munchausen by doctor to evolve, which reflects a continued search for physiologic aberration by physicians reinforcing the perception there is an underlying treatable and undiagnosed biological explanation.

The development of FPS, therefore, seems to be attributable to a combination of several biopsychosocial factors. However, there is a serious need for further exploration into these factors, their implications, and their contribution to FPS as a whole. Just as there needs to be consensus on the language we use to talk about all FPS, we need to develop a comprehensive view of the onset and maintenance of all FPS.

\section{The impact of FPS}

Unfortunately, the complexities of FPS do not stop with unclear diagnostic terminologies and causal factors. The complex challenges that patients with FPS experience are numerous and often difficult to discern from patients with a pathophysiological explanation for their pain. Youth with chronic pain experience decreased quality of life and family disruptions, ${ }^{68}$ disturbed sleep and inability to pursue hobbies, ${ }^{69}$ school absenteeism and reduced socialization with friends, ${ }^{70}$ and increased functional disability. ${ }^{71}$ When specifically examining children and adolescents with FPS, the literature is sparse, but does indicate that youth with FPS experience significant decrease across most domains of life in 
comparison with healthy peers and even peers with organic disease. ${ }^{72-74}$ In examining the unique experience of youth with FPS, three prominent themes emerged: 1) the perception of others, 2) impact on the family, and 3) psychiatric morbidity.

\section{Perception of others}

\section{Peers}

Children and adolescents with FPS do appear to face distinct difficulties socially. Guite et $\mathrm{a}^{75}$ revealed that healthy children reported greater liking of peers with pain conditions of an organic etiology and perceived their symptoms as more severe than peers having pain symptoms without organic disease. Additionally, adolescents with an FPS disorder, such as fibromyalgia, were perceived by healthy peers as being more sensitive/isolated and having significantly fewer friendships. ${ }^{76}$ It is likely that youth affected by FPS syndromes recognize the negative perceptions held by their peers. It has been demonstrated that adults with functional somatic syndromes report higher levels of perceived stigma when compared with a matched medical group; ${ }^{77}$ further research is needed to examine this same phenomenon in children.

\section{Medical personnel}

In addition to negative perceptions held by peers, children with FPS are impacted by views from medical staff. In some cases, only a small percentage of school nurses believe recurrent abdominal pain to be a serious disease and suspect that children presenting to their offices with this condition are lazy, faking, or seeking attention. ${ }^{78}$ Similarly, when interviewed about views on adults affected with IBS, doctors often express frustration and can point out negative characteristics of these types of patients, while the patients themselves feel discredited and trivialized. ${ }^{79}$ Very little research is available to determine if children with FPS hold similar views on the medical encounter as their adult counterparts. However, pediatric patients have recalled times when the doctors dismissed their pain when no evidence for an organic cause for the pain was found; furthermore, parents have described feelings of being judged and perceived medical professionals to be suspicious of the pain. ${ }^{80}$ Parents of youth with FPS have also previously demonstrated lower physician satisfaction when given a functional diagnosis for their children's pain symptoms versus parents given an organic diagnosis. ${ }^{81}$

To compound the problem, the treatment providers are often struggling themselves to adequately address the needs of patients with FPS. It is not uncommon for physicians to feel "drained" by these patients due in part by not meeting their needs and expectations as care providers. ${ }^{82}$ Physicians frequently struggle to explain the ambiguous and complex nature of symptoms resulting from FPS to their patients; ${ }^{83}$ one can only imagine how this is compounded when addressing the patient and his/her parents. This topic warrants future investigation.

\section{Impact on families}

Given that children and adolescents live within a family system, the consequences of their pain typically extend across all family members, particularly parents. Notably, much of the available research represents the views and experiences of mothers. ${ }^{84-91}$ More exploration is needed in this field in order to understand the perspectives of the fathers of children and adolescents with FPS and determine if/how they differ from the mothers' perspectives.

Current research has established that mothers of children with FPS report significant effects on work and family life, including decreased productivity and increased conflicts in the household due to their children's pain. ${ }^{85}$ Not surprisingly, Lipani and Walker ${ }^{86}$ demonstrated that maternal worries, limitations in activities, and time constraints are related to pain severity in children with FPS. On a more critical level, the majority of parents report clinically significant scores on measures of distress, anxiety, and depression in a recent study. ${ }^{91}$

Increases in maternal distress may, in part, be explained by parental hardship in dealing with the ambiguity of FPS in their children and the search for some sort of identity or "illness label" to authenticate the symptom(s) for the child, family, and school. ${ }^{85}$ This frustrating and exhausting process has been described as a "struggle for control and coherence" and torturous knowing that, as a parent, one cannot make the pain go away. ${ }^{92}$ In addition to this, mothers describe a feeling of responsibility for the pain and threat to their parental role. ${ }^{84}$ Direct correlations have been found between perceived parental responsibility for the child's pain and poorer family functioning/parenting stress. ${ }^{88}$

Van Tilburg et $\mathrm{al}^{93}$ have touched on two central conflicts reflecting the cognitions of parents' of children with FPS: pain is real and the desire for care. Parents have struggled with this idea of "real" pain, because many times, they have seen their children experience obvious physical symptoms, but are also able to recognize the contribution of complex psychological factors. No matter the contributing factors, though, parents of children and adolescents with FPS increasingly act on their desire for care. Connelly et al ${ }^{89}$ determined that health care utilization might be driven, at least partially, by 
parental perceptions of high child vulnerability. It has also been shown that extensive medical investigations by means of laboratory tests and imaging studies are not pursued entirely for the reassurance of the parents of children with FPS; doctors need the comfort as well. ${ }^{94}$ And since research has identified child FPS can persist into adulthood, ${ }^{95-97}$ it is likely that health care use will remain high for these patients whose pain continues without a clear diagnosis or etiological understanding.

\section{Psychiatric morbidity: another layer of complexity}

Despite no clear directional evidence regarding the relationship between pediatric FPS and psychiatric symptoms, psychiatric morbidity is quite common in this population. It has been determined that nearly $35 \%$ of a pediatric FPS sample had a clinically relevant psychiatric disorder, the most frequent being anxiety, affective, and disruptive disorders. ${ }^{98}$ The prevalence and type of psychiatric disorder (ie, internalizing, externalizing) seem to vary with type of pain and patient sex. Egger et $\mathrm{al}^{99}$ found that female children and adolescents who reported primarily stomach pain were more likely to also have a co-occurring anxiety disorder, while having musculoskeletal pains was more associated with depression. On the other hand, male children and adolescents were more likely to exhibit disruptive disorders, such as attention-deficit/hyperactivity disorder and oppositional defiant disorder, in association with stomach pain. This discrepancy between the sexes reflects general prevalence rates with higher rates of internalizing disorders among females and higher rates of externalizing disorders among males. Overall, however, functional abdominal pain patients seem to present with alarmingly high rates of psychological disorders. ${ }^{100}$ Future research should determine why this population is particularly vulnerable to psychiatric difficulties. Additionally, psychiatric conditions co-occurring with FPS in the pediatric population is a relevant issue in other cultures. For example, Imran et $\mathrm{al}^{101}$ recently determined that Pakistani children with FPS also present with more anxiety and depressive symptoms than children with diagnosed medical conditions and healthy controls.

\section{Treatment options for FPS}

Taking into account the high prevalence rates and unique, challenging impacts FPS has on youth and their families, it is critical to identify treatment options for this population. Due to the uncertain nature of FPS and the varying phenotypes, uniform recommended treatment has not been established. Currently, more well-designed longitudinal studies are needed to determine the exact prognoses of FPS treatment options. With this being said, addressing FPS, and chronic pain in general, with a multidisciplinary approach proves to be one of the most popular intervention strategies and has demonstrated much success in both inpatient and outpatient settings. ${ }^{102,103}$ The multidisciplinary approach acknowledges the totality of the systems that interact during an individual's experience of pain, including biological, psychological, social, and environmental factors. ${ }^{104}$ It should also be rehabilitative in nature, which reframes the goal of the treatment process from "curing" to "coping" with the pain problem and puts responsibility for treatment success in the hands of the patients. ${ }^{105}$ Instead of focusing on removing the pain, the ultimate goal in treatments is to increase functioning. ${ }^{106}$ Upon review of limited research on multidisciplinary treatment programs, it is evident that most involve a combination of three types of therapy: 1) psychological, 2) physical, and 3) pharmacological.

\section{Psychological therapy}

CBT is being increasingly studied within the FPS population. In reference to FPS, CBT provides the opportunity for clinicians to target the negative symptom-related beliefs and behaviors that perpetuate dysfunction in many patients across a wide array of FPS. ${ }^{107}$ During individual CBT sessions, a pediatric psychologist typically helps a patient identify characteristics, such as pain catastrophizing, fear of pain, and psychosocial stressors, that are potentially contributing to the pain as well as provides techniques to actively cope with and manage the painful episodes. ${ }^{47,108}$ Some CBT programs for FPS patients also involve acceptance, interpersonal skills training, and relapse prevention modules in group settings. ${ }^{102}$ Still others require a family therapy component, which has produced successful results in comparison to standard care. ${ }^{109}$ Family involvement allows for the identification of parents' own catastrophizing, fearful, and overprotective behaviors that have proven to be maladaptive and influence the child in pain. ${ }^{110-112}$ The parent learns to serve as a model and reinforcer of responding to pain in adaptive healthy ways. ${ }^{113}$ In addition to CBT, evidence supporting hypnotherapy is emerging. This approach teaches children to alter the perception of uncomfortable physiological sensations in their body. ${ }^{114}$ A recent systematic review of randomized clinical trials of gut-directed hypnotherapy identified greater improvements in pain that were sustained at follow-up in comparison to standard care. ${ }^{115}$ 


\section{Physical therapy}

As stated previously, the primary aim of pain management for youth with FPS is to restore function and participation in daily activities. Physical rehabilitation is a common and often essential treatment component. ${ }^{116}$ More specifically, graded exercise allows for physical activity that gradually and slowly increases over time, typically after the child has established a hierarchical list of activities where each activity must be completed before pursing the next based on successful execution rather than pain reduction. ${ }^{117}$ Due to the unique, complex nature of FPS patients, it is likely that graded exercise will not be beneficial for the entire population. Alternatively, yoga may serve to decrease physical and emotional pain-related symptoms. ${ }^{118,119}$

\section{Pharmacological therapy}

When considering pharmacological therapy with the goal of decreasing peripheral disturbances, research is variable and generally weak, as most evidence points to focusing on function versus symptom alleviation with FPS. ${ }^{120}$ There is still considerable use of anticonvulsants for pediatric pain management. Additionally, antidepressants have gained traction with joint effects on pain modulation and associated mood states. ${ }^{121-123}$ Evidence within the pediatric population is lacking; however, few studies demonstrate that antidepressant medication taken for FPS shows promising response rates in youth through improvements in quality of life as well as decreases in pain and psychiatric symptoms. ${ }^{124-127}$ With this being said, current research has reported greater success in decreasing pain intensity and duration by utilizing pharmacological treatment in combination with psychological intervention as opposed to standard pharmacological treatment alone. Such multifaceted treatment regimens also have the potential to provide secondary positive impacts on child psychological and social variables. ${ }^{128}$ Still, more longitudinal studies are necessary to determine the effectiveness of antidepressant medications in the pediatric FPS population and uncover possible harmful side effects.

\section{Where to go from here for FPS?}

We have just scratched the surface in properly addressing FPS in childhood. It is apparent, though, that to better address FPS in childhood, we must shift our clinical and research approach.

\section{In the clinic}

1. Empathize: Patients with FPS are seeking, and deserve, validation. We must clarify that a lack of definitive answers does not mean that we have given up on them or do not believe them. In fact, it should reflect that we are even more invested in finding the most appropriate treatment that is going to uniquely address their child's situation.

2. Communicate: In communicating with the patient and family about chronic pain, a coherent explanation should be given to increase patient knowledge of pain-related biology and shift conceptions of pain. ${ }^{129}$ Additionally, communication between providers who have cared for the patient is key to offering a uniform treatment approach.

3. Normalize: Psychiatric comorbidity among youth with FPS is common. It should neither be trivialized nor become the sole focus of the child's pain treatment intervention, even in extreme cases of Munchausen. A multidisciplinary approach that includes medical, physical, and psychology teams working together is essential for treatment success.

4. Biobehavioral interventions as a first-line treatment: Biobehavioral approaches to the treatment of pain have proven efficacy, without side effects, and bringing these treatments online early reduces the stigma associated with the belief "Well, the doctors didn't know what else to do so they sent us to a psychologist". ${ }^{130}$ Importantly, many of these strategies are now readily accessible through the internet or through apps. ${ }^{131}$

\section{In both the clinic and in the domain of research}

5. Pick a name: Decide on proper, nonjudgmental nomenclature that destigmatizes these conditions, such as the proposed term, primary pain disorders. ${ }^{20}$

6. All use the same name: Ensure that this nomenclature is implemented across specialists to ensure clinicians treating these patients and researchers studying these patients are speaking a common language.

7. Put some of these theories to the test: It is possible that patients with the same symptom presentation may actually have different drivers that serve to maintain their condition, thus perhaps it is worthwhile to group patients not by their phenotype (eg, abdominal pain) but rather the underlying mechanism (eg, neuronal sensitization) to formulate treatment recommendations and new research hypotheses. The use of "big data" can also aid this effort.

In closing, the momentum is building to garner better answers and treatment for children with FPS, and there are many reasons to believe it will only get better. With this 
being said, FPS should become a high-priority topic for future research.

\section{Acknowledgments}

This study was supported by an NIH grant (K23 HD067202) awarded to LES, the Sara Page Mayo Endowment for Pediatric Pain Research and Treatment, and the Department of Anesthesiology, Perioperative and Pain Medicine at Boston Children's Hospital.

\section{Disclosure}

The authors report no conflicts of interest in this work.

\section{References}

1. Bourke JH, Langford RM, White PD. The common link between functional somatic syndromes may be central sensitisation. $J$ Psychosom Res. 2015;78(3):228-236.

2. Buskila D. Pediatric fibromyalgia. Rheum Dis Clin North Am. 2009; 35(2):253-261.

3. Clayton EW. Beyond myalgic encephalomyelitis/chronic fatigue syndrome: an IOM report on redefining an illness. JAMA. 2015; 313(11):1101-1102.

4. Baker R, Shaw EJ. Diagnosis and management of chronic fatigue syndrome or myalgic encephalomyelitis (or encephalopathy): summary of NICE guidance. BMJ. 2007;335(7617):446-448.

5. Sommer C. Fibromyalgia: a clinical update. Pain Clin Updates. 2010;XVIII(4).

6. National Academy of Sciences. Beyond Myalgic Encephalomyelitis/ Chronic Fatigue Syndrome: Redefining an Illness. Washington, DC: National Academy of Sciences; 2015.

7. Henningsen P, Jakobsen T, Schiltenwolf M, Weiss MG. Somatization revisited: diagnosis and perceived causes of common mental disorders. J Nerv Mental Dis. 2005;193(2):85-92.

8. Henningsen P, Zimmermann T, Sattel H. Medically unexplained physical symptoms, anxiety, and depression: a meta-analytic review. Psychosom Med. 2003;65(4):528-533.

9. Hanel G, Henningsen P, Herzog W, et al. Depression, anxiety, and somatoform disorders: vague or distinct categories in primary care? Results from a large cross-sectional study. J Psychosom Res. 2009;67(3):189-197.

10. Creed F. Medically unexplained symptoms - blurring the line between "mental" and "physical" in somatoform disorders. J Psychosom Res. 2009;67(3):185-187.

11. Speciali JG, Dach F. Temporomandibular dysfunction and headache disorder. Headache. 2015;55(Suppl 1):72-83.

12. Yunus MB, Masi AT. Juvenile primary fibromyalgia syndrome. A clinical study of thirty-three patients and matched normal controls. Arthritis Rheum. 1985;28(2):138-145.

13. Konijnenberg AY, De Graeff-Meeder ER, Kimpen JL, van der Hoeven J, Buitelaar JK, Uiterwaal CS. Children with unexplained chronic pain: do pediatricians agree regarding the diagnostic approach and presumed primary cause? Pediatrics. 2004;114(5):1220-1226.

14. Smith RC, Dwamena FC. Classification and diagnosis of patients with medically unexplained symptoms. J Gen Intern Med. 2007;22(5): 685-691.

15. Fantoni F, Salvetti G, Manfredini D, Bosco M. Current concepts on the functional somatic syndromes and temporomandibular disorders. Stomatologija. 2007;9(1):3-9.

16. Dell ML, Campo JV. Somatoform disorders in children and adolescents. Psychiatr Clin North Am. 2011;34(3):643-660.

17. Campo JV, Fritsch SL. Somatization in children and adolescents. J Am Acad Child Adolesc Psychiatr. 1994;33(9):1223-1235.
18. Nimnuan C, Rabe-Hesketh S, Wessely S, Hotopf M. How many functional somatic syndromes? J Psychosom Res. 2001;51(4):549-557.

19. Rief W, Isaac M. The future of somatoform disorders: somatic symptom disorder, bodily distress disorder or functional syndromes? Curr Opin Psychiatr. 2014;27(5):315-319.

20. Schechter NL. Functional pain: time for a new name. JAMA Pediatr. 2014;168(8):693-694.

21. Mayou R. Is the DSM- 5 chapter on somatic symptom disorder any better than DSM-IV somatoform disorder? Br J Psychiatr. 2014;204(6): 418-419.

22. Mayou R, Kirmayer LJ, Simon G, Kroenke K, Sharpe M. Somatoform disorders: time for a new approach in DSM-V. Am J Psychiatr. 2005;162(5):847-855.

23. Picariello F, Ali S, Moss-Morris R, Chalder T. The most popular terms for medically unexplained symptoms: the views of CFS patients. J Psychosom Res. 2015;78(5):420-426.

24. Marks EM, Hunter MS. Medically unexplained symptoms: an acceptable term? Br J Pain. Epub 2014 May 27.

25. Jason LA, Taylor RR, Stepanek Z, Plioplys S. Attitudes regarding chronic fatigue syndrome: the importance of a name. J Health Psychol. 2001;6(1):61-71.

26. Hamilton WT, Gallagher AM, Thomas JM, White PD. The prognosis of different fatigue diagnostic labels: a longitudinal survey. Fam Pract. 2005;22(4):383-388.

27. Eminson DM. Medically unexplained symptoms in children and adolescents. Clin Psychol Rev. 2007;27(7):855-871.

28. King S, Chambers CT, Huguet A, et al. The epidemiology of chronic pain in children and adolescents revisited: a systematic review. Pain. 2011;152(12):2729-2738.

29. Krogh AB, Larsson B, Linde M. Prevalence and disability of headache among Norwegian adolescents: a cross-sectional school-based study. Cephalalgia. Epub 2015 Feb 26.

30. Groenewald CB, Essner BS, Wright D, Fesinmeyer MD, Palermo TM. The economic costs of chronic pain among a cohort of treatment-seeking adolescents in the United States. J Pain. 2014;15(9):925-933.

31. Escobar MA Jr, Lustig D, Pflugeisen BM, et al. Fructose intolerance/ malabsorption and recurrent abdominal pain in children. $J$ Pediatr Gastroenterol Nutr. 2014;58(4):498-501.

32. Oaklander AL, Klein MM. Evidence of small-fiber polyneuropathy in unexplained, juvenile-onset, widespread pain syndromes. Pediatrics. 2013;131(4):e1091-e1100.

33. van Ravenzwaaij J, Olde Hartman T, van Ravesteijn H, Eveleigh R, van Rijswijk E, Lucassen P. Explanatory models of medically unexplained symptoms: a qualitative analysis of the literature. Ment Health Fam Med. 2010;7(4):223-231.

34. Rief W, Broadbent E. Explaining medically unexplained symptomsmodels and mechanisms. Clin Psychol Rev. 2007;27(7):821-841.

35. Rosen JM, Cocjin JT, Schurman JV, Colombo JM, Friesen CA. Visceral hypersensitivity and electromechanical dysfunction as therapeutic targets in pediatric functional dyspepsia. World J Gastrointest Pharmacol Ther. 2014;5(3):122-138.

36. Faure C, Giguere L. Functional gastrointestinal disorders and visceral hypersensitivity in children and adolescents suffering from Crohn's disease. Inflamm Bowel Dis. 2008;14(11):1569-1574.

37. Castilloux J, Noble A, Faure C. Is visceral hypersensitivity correlated with symptom severity in children with functional gastrointestinal disorders? J Pediatr Gastroenterol Nutr. 2008;46(3): $272-278$.

38. Dantzer R. Somatization: a psychoneuroimmune perspective. Psychoneuroendocrinology. 2005;30(10):947-952.

39. Dimsdale JE, Dantzer R. A biological substrate for somatoform disorders: importance of pathophysiology. Psychosom Med. 2007;69(9): $850-854$.

40. Irwin MR. Inflammation at the intersection of behavior and somatic symptoms. Psychiatr Clin North Am. 2011;34(3):605-620.

41. Rief W, Barsky AJ. Psychobiological perspectives on somatoform disorders. Psychoneuroendocrinology. 2005;30(10):996-1002. 
42. Barke A, Gassmann J, Kroner-Herwig B. Cognitive processing styles of children and adolescents with headache and back pain: a longitudinal epidemiological study. J Pain Res. 2014;7:405-414.

43. Duddu V, Isaac MK, Chaturvedi SK. Somatization, somatosensory amplification, attribution styles and illness behaviour: a review. Int Rev Psychiatr. 2006;18(1):25-33.

44. Scholz OB, Ott R, Sarnoch H. Proprioception in somatoform disorders. Behav Res Ther. 2001;39(12):1429-1438.

45. Sowder E, Gevirtz R, Shapiro W, Ebert C. Restoration of vagal tone: a possible mechanism for functional abdominal pain. Appl Psychophysiol Biofeedback. 2010;35(3):199-206.

46. Tak LM, Janssens KA, Dietrich A, Slaets JP, Rosmalen JG. Agespecific associations between cardiac vagal activity and functional somatic symptoms: a population-based study. Psychother Psychosom. 2010;79(3):179-187.

47. Simons LE, Kaczynski KJ. The fear avoidance model of chronic pain: examination for pediatric application. J Pain. 2012;13(9):827-835.

48. Buffington CA. Developmental influences on medically unexplained symptoms. Psychother Psychosom. 2009;78(3):139-144.

49. Warner CM, Colognori D, Kim RE, et al. Cognitive-behavioral treatment of persistent functional somatic complaints and pediatric anxiety: an initial controlled trial. Depress Anxiety. 2011;28(7):551-559.

50. Connelly M, Bickel J. Chronic daily headache in children and adolescents: science and conjecture. Pain Manage. 2013;3(1):47-58.

51. Stuart S, Noyes R Jr. Attachment and interpersonal communication in somatization. Psychosomatics. 1999;40(1):34-43.

52. Davies KA, Macfarlane GJ, McBeth J, Morriss R, Dickens C. Insecure attachment style is associated with chronic widespread pain. Pain. 2009; 143(3):200-205.

53. Waller E, Scheidt CE, Hartmann A. Attachment representation and illness behavior in somatoform disorders. J Nerv Ment Dis. 2004;192(3): 200-209.

54. Kozlowska K. Attachment relationships shape pain-signaling behavior. J Pain. 2009;10(10):1020-1028.

55. Kozlowska K, Khan R. A developmental, body-oriented intervention for children and adolescents with medically unexplained chronic pain. Clin Child Psychol Psychiatr. 2011;16(4):575-598.

56. Kozlowska K, Williams LM. Self-protective organization in children with conversion and somatoform disorders. J Psychosom Res. 2009; 67(3):223-233.

57. Last CG. Somatic complaints in anxiety disordered children. J Anxiety Dis. 1991;5(2):125-138.

58. Ewart CK, Elder GJ, Laird KT, Shelby GD, Walker LS. Can agonistic striving lead to unexplained illness? Implicit goals, pain tolerance, and somatic symptoms in adolescents and adults. Health Psychol. 2014; 33(9):977-985.

59. Evans S, Keenan TR, Shipton EA. Psychosocial adjustment and physical health of children living with maternal chronic pain. J Paediatr Child Health. 2007;43(4):262-270.

60. Sieh DS, Visser-Meily JM, Meijer AM. Differential outcomes of adolescents with chronically ill and healthy parents. J Child Fam Stud. 2013;22(2):209-218.

61. Levy RL. Exploring the intergenerational transmission of illness behavior: from observations to experimental intervention. Ann Behav Med. 2011;41(2):174-182.

62. Blanchard EB, Keefer L, Lackner JM, Galovski TE, Krasner S, Sykes MA. The role of childhood abuse in Axis I and Axis II psychiatric disorders and medical disorders of unknown origin among irritable bowel syndrome patients. J Psychosom Res. 2004;56(4):431-436.

63. Blanchard EB, Keefer L, Payne A, Turner SM, Galovski TE. Early abuse, psychiatric diagnoses and irritable bowel syndrome. Behav Res Ther. 2002;40(3):289-298.

64. Lackner JM, Gudleski GD, Blanchard EB. Beyond abuse: the association among parenting style, abdominal pain, and somatization in IBS patients. Behav Res Ther. 2004;42(1):41-56.

65. Terre L, Ghiselli W. A developmental perspective on family risk factors in somatization. J Psychosom Res. 1997;42(2):197-208.
66. Bass C, Glaser D. Early recognition and management of fabricated or induced illness in children. Lancet. 2014;383(9926):1412-1421.

67. Jaghab K, Skodnek KB, Padder TA. Munchausen's syndrome and other factitious disorders in children: case series and literature review. Psychiatry. 2006;3(3):46-55.

68. Hunfeld JA, Perquin CW, Duivenvoorden HJ, et al. Chronic pain and its impact on quality of life in adolescents and their families. J Pediatr Psychol. 2001;26(3):145-153.

69. Haraldstad K, Sorum R, Eide H, Natvig GK, Helseth S. Pain in children and adolescents: prevalence, impact on daily life, and parents' perception, a school survey. Scand J Caring Sci. 2011;25(1):27-36.

70. Roth-Isigkeit A, Thyen U, Stoven H, Schwarzenberger J, Schmucker P. Pain among children and adolescents: restrictions in daily living and triggering factors. Pediatrics. 2005;115(2):e152-e162.

71. Kashikar-Zuck S, Goldschneider KR, Powers SW, Vaught MH, Hershey AD. Depression and functional disability in chronic pediatric pain. Clin J Pain. 2001;17(4):341-349.

72. Varni JW, Bendo CB, Nurko S, et al. Health-related quality of life in pediatric patients with functional and organic gastrointestinal diseases. J Pediatr. 2015;166(1):85-90.

73. Konijnenberg AY, Uiterwaal CS, Kimpen JL, van der Hoeven J, Buitelaar JK, de Graeff-Meeder ER. Children with unexplained chronic pain: substantial impairment in everyday life. Arch Dis Childhood. 2005;90(7):680-686.

74. Drossman DA, Li Z, Leserman J, Toomey TC, Hu YJ. Health status by gastrointestinal diagnosis and abuse history. Gastroenterology. 1996;110(4):999-1007.

75. Guite JW, Walker LS, Smith CA, Garber J. Children's perceptions of peers with somatic symptoms: the impact of gender, stress, and illness. J Pediatr Psychol. 2000;25(3):125-135.

76. Kashikar-Zuck S, LynchAM, Graham TB, Swain NF, Mullen SM, Noll RB. Social functioning and peer relationships of adolescents with juvenile fibromyalgia syndrome. Arthritis Rheum. 2007;57(3):474-480.

77. Looper KJ, Kirmayer LJ. Perceived stigma in functional somatic syndromes and comparable medical conditions. J Psychosom Res. 2004;57(4):373-378.

78. Youssef NN, Murphy TG, Schuckalo S, Intile C, Rosh J. School nurse knowledge and perceptions of recurrent abdominal pain: opportunity for therapeutic alliance? Clin Pediatr. 2007;46(4):340-344.

79. Dixon-Woods M, Critchley S. Medical and lay views of irritable bowel syndrome. Fam Pract. 2000;17(2):108-113.

80. Carter B. Chronic pain in childhood and the medical encounter: professional ventriloquism and hidden voices. Qual Health Res. 2002;12(1): $28-41$.

81. Williams SE, Smith CA, Bruehl SP, Gigante J, Walker LS. Medical evaluation of children with chronic abdominal pain: impact of diagnosis, physician practice orientation, and maternal trait anxiety on mothers' responses to the evaluation. Pain. 2009;146(3):283-292.

82. Drossman DA. Challenges in the physician-patient relationship: feeling “drained”. Gastroenterology. 2001;121(5):1037-1038.

83. Olde Hartman TC, Hassink-Franke LJ, Lucassen PL, van Spaendonck KP, van Weel C. Explanation and relations. How do general practitioners deal with patients with persistent medically unexplained symptoms: a focus group study. BMC Fam Pract. 2009; 10:68.

84. Smart S, Cottrell D. Going to the doctors: the views of mothers of children with recurrent abdominal pain. Child Care Health Dev. 2005;31(3): 265-273.

85. Morris A, Ogden J. Making sense of children's medically unexplained symptoms: managing ambiguity, authenticity and responsibility. Psychol Health Med. 2012;17(3):285-294.

86. Lipani TA, Walker LS. Children's appraisal and coping with pain: relation to maternal ratings of worry and restriction in family activities. J Pediatr Psychol. 2006;31(7):667-673.

87. Levy RL, Langer SL, Walker LS, Feld LD, Whitehead WE. Relationship between the decision to take a child to the clinic for abdominal pain and maternal psychological distress. Arch Pediatr Adolesc Med. 2006; 160(9):961-965. 
88. Guite JW, Logan DE, McCue R, Sherry DD, Rose JB. Parental beliefs and worries regarding adolescent chronic pain. Clin J Pain. 2009; 25(3):223-232.

89. Connelly M, Anthony KK, Schanberg LE. Parent perceptions of child vulnerability are associated with functioning and health care use in children with chronic pain. J Pain Symptom Manage. 2012;43(5):953-960.

90. Campo JV, Bridge J, Lucas A, et al. Physical and emotional health of mothers of youth with functional abdominal pain. Arch Pediatr Adolesc Med. 2007;161(2):131-137.

91. Cohen LL, Vowles KE, Eccleston C. Parenting an adolescent with chronic pain: an investigation of how a taxonomy of adolescent functioning relates to parent distress. J Pediatr Psychol. 2010;35(7):748-757.

92. Jordan AL, Eccleston C, Osborn M. Being a parent of the adolescent with complex chronic pain: an interpretative phenomenological analysis. Eur J Pain. 2007;11(1):49-56.

93. van Tilburg MA, Chitkara DK, Palsson OS, Levy RL, Whitehead WE. Parental worries and beliefs about abdominal pain. J Pediatr Gastroenterol Nutr. 2009;48(3):311-317.

94. Dhroove G, Chogle A, Saps M. A million-dollar work-up for abdominal pain: is it worth it? J Pediatr Gastroenterol Nutr. 2010;51(5): 579-583.

95. Howell S, Poulton R, Talley NJ. The natural history of childhood abdominal pain and its association with adult irritable bowel syndrome: birth-cohort study. Am J Gastroenterol. 2005;100(9):2071-2078.

96. Mulvaney S, Lambert EW, Garber J, Walker LS. Trajectories of symptoms and impairment for pediatric patients with functional abdominal pain: a 5-year longitudinal study. JAm Acad Child Adolesc Psychiatr. 2006;45(6):737-744.

97. Kashikar-Zuck S, Cunningham N, Sil S, et al. Long-term outcomes of adolescents with juvenile-onset fibromyalgia in early adulthood. Pediatrics. 2014;133(3):e592-e600.

98. Knook LM, Konijnenberg AY, van der Hoeven J, et al. Psychiatric disorders in children and adolescents presenting with unexplained chronic pain: what is the prevalence and clinical relevancy? Eur Child Adolesc Psychiatr. 2011;20(1):39-48.

99. Egger HL, Costello EJ, Erkanli A, Angold A. Somatic complaints and psychopathology in children and adolescents: stomach aches, musculoskeletal pains, and headaches. Am Acad Child Adolesc Psychiatry. 1999;38(7):852-860.

100. Campo JV, Bridge J, Ehmann M, et al. Recurrent abdominal pain, anxiety, and depression in primary care. Pediatrics. 2004;113(4):817-824.

101. Imran N, Ani C, Mahmood Z, Hassan KA, Bhatti MR. Anxiety and depression predicted by medically unexplained symptoms in Pakistani children: a case-control study. J Psychosom Res. 2014; 76(2):105-112.

102. Pieh C, Neumeier S, Loew T, et al. Effectiveness of a multimodal treatment program for somatoform pain disorder. Pain Pract. 2014;14(3): E146-E151.

103. Logan DE, Conroy C, Sieberg CB, Simons LE. Changes in willingness to self-manage pain among children and adolescents and their parents enrolled in an intensive interdisciplinary pediatric pain treatment program. Pain. 2012;153(9):1863-1870.

104. Zeltzer L, Bursch B, Walco G. Pain responsiveness and chronic pain: a psychobiological perspective. J Dev Behav Pediatr. 1997;18(6): 413-422.

105. Campo JV, Fritz G. A management model for pediatric somatization. Psychosomatics. 2001;42(6):467-476.

106. Klineberg E, Rushworth A, Bibby H, Bennett D, Steinbeck K, Towns S. Adolescent chronic fatigue syndrome and somatoform disorders: a prospective clinical study. J Paediatr Child Health. 2014;50(10) $775-781$.

107. Kroenke K, Swindle R. Cognitive-behavioral therapy for somatization and symptom syndromes: a critical review of controlled clinical trials. Psychother Psychosom. 2000;69(4):205-215.

108. Maynard CS, Amari A, Wieczorek B, Christensen JR, Slifer KJ. Interdisciplinary behavioral rehabilitation of pediatric pain-associated disability: retrospective review of an inpatient treatment protocol. J Pediatr Psychol. 2010;35(2):128-137.
109. Sanders MR, Shepherd RW, Cleghorn G, Woolford H. The treatment of recurrent abdominal pain in children: a controlled comparison of cognitive-behavioral family intervention and standard pediatric care. J Consult Clin Psychol. 1994;62(2):306-314.

110. Logan DE, Simons LE, Carpino EA. Too sick for school? Parent influences on school functioning among children with chronic pain. Pain. 2012;153(2):437-443.

111. Simons LE, Smith A, Kaczynski K, Basch M. Living in fear of your child's pain: the parent fear of pain questionnaire. Pain. 2015;156(4): 694-702.

112. Wilson AC, Moss A, Palermo TM, Fales JL. Parent pain and catastrophizing are associated with pain, somatic symptoms, and pain-related disability among early adolescents. J Pediatr Psychol. 2014;39(4): 418-426

113. Levy RL, Langer SL, Walker LS, et al. Cognitive-behavioral therapy for children with functional abdominal pain and their parents decreases pain and other symptoms. Am J Gastroenterol. 2010;105(4): 946-956.

114. Chen E, Joseph MH, Zeltzer LK. Behavioral and cognitive interventions in the treatment of pain in children. Pediatr Clin North Am. 2000;47(3):513-525.

115. Rutten JM, Reitsma JB, Vlieger AM, Benninga MA. Gut-directed hypnotherapy for functional abdominal pain or irritable bowel syndrome in children: a systematic review. Arch Dis Childhood. 2013;98(4) 252-257.

116. Kashikar-Zuck S, Flowers SR, Strotman D, Sil S, Ting TV, Schikler KN. Physical activity monitoring in adolescents with juvenile fibromyalgia: findings from a clinical trial of cognitive-behavioral therapy. Arthritis Care Res. 2013;65(3):398-405.

117. Calvert P, Jureidini J. Restrained rehabilitation: an approach to children and adolescents with unexplained signs and symptoms. Arch Dis Child. 2003;88(5):399-402.

118. Oka T, Tanahashi T, Chijiwa T, Lkhagvasuren B, Sudo N, Oka K. Isometric yoga improves the fatigue and pain of patients with chronic fatigue syndrome who are resistant to conventional therapy: a randomized, controlled trial. Biopsychosoc Med. 2014;8(1):27.

119. Kuttner L, Chambers CT, Hardial J, Israel DM, Jacobson K, Evans K. A randomized trial of yoga for adolescents with irritable bowel syndrome. Pain Res Manage. 2006;11(4):217-223.

120. Henningsen P, Zipfel S, Herzog W. Management of functional somatic syndromes. Lancet. 2007;369(9565):946-955.

121. Hauser W, Bernardy K, Uceyler N, Sommer C. Treatment of fibromyalgia syndrome with antidepressants: a meta-analysis. JAMA. 2009;301(2):198-209.

122. Goldenberg DL, Burckhardt C, Crofford L. Management of fibromyalgia syndrome. JAMA. 2004;292(19):2388-2395.

123. Fishbain DA, Cutler RB, Rosomoff HL, Rosomoff RS. Do antidepressants have an analgesic effect in psychogenic pain and somatoform pain disorder? A meta-analysis. Psychosom Med. 1998;60(4): 503-509.

124. Bahar RJ, Collins BS, Steinmetz B, Ament ME. Double-blind placebocontrolled trial of amitriptyline for the treatment of irritable bowel syndrome in adolescents. J Pediatr. 2008;152(5):685-689.

125. Teitelbaum JE, Arora R. Long-term efficacy of low-dose tricyclic antidepressants for children with functional gastrointestinal disorders. J Pediatr Gastroenterol Nutr. 2011;53(3):260-264.

126. Campo JV, Perel J, Lucas A, et al. Citalopram treatment of pediatric recurrent abdominal pain and comorbid internalizing disorders: an exploratory study. J Am Acad Child Adolesc Psychiatr. 2004;43(10): 1234-1242.

127. Sezer T, Kandemir H, Alehan F. A randomized trial comparing amitriptyline versus topiramate for the prophylaxis of chronic daily headache in pediatric patients. Int $J$ Neurosci. 2013;123(8):553-556.

128. Schurman JV, Wu YP, Grayson P, Friesen CA. A pilot study to assess the efficacy of biofeedback-assisted relaxation training as an adjunct treatment for pediatric functional dyspepsia associated with duodenal eosinophilia. J Pediatr Psychol. 2010;35(8):837-847. 
129. Moseley GL, Butler DS. Fifteen years of explaining pain: the past, present, and future. J Pain. Epub 2015 Jun 5.

130. Eccleston C, Fisher E, Law E, Bartlett J, Palermo TM. Psychological interventions for parents of children and adolescents with chronic illness. Cochrane Database Syst Rev. Epub 2015 Apr 15.
131. Smith K, Iversen C, Kossowsky J, O’Dell S, Gambhir R, Coakley R. Apple apps for the management of pediatric pain and pain-related stress. Clin Pract Pediatr Psychol. 2015;3(2):93-107.

\section{Publish your work in this journal}

The Journal of Pain Research is an international, peer-reviewed, open access, online journal that welcomes laboratory and clinical findings in the fields of pain research and the prevention and management of pain. Original research, reviews, symposium reports, hypothesis formation and commentaries are all considered for publication.

\section{Dovepress}

The manuscript management system is completely online and includes a very quick and fair peer-review system, which is all easy to use. Visit http://www.dovepress.com/testimonials.php to read real quotes from published authors.

Submit your manuscript here: http://www.dovepress.com/journal-of-pain-research-journal 